\title{
Thermally Safe Operation of a Semibatch Reactor for Liquid-Liquid Reactions - Fast Reactions
}

\author{
Metske Steensma and K. Roel Westerterp*
}

Accumulation of the reactant supplied to a cooled semibatch reactor (SBR) will occur if the mass transfer rate across the interface is insufficient to keep pace with the supply rate. Then, due to a low starting temperature or supercooling, the reaction temperature does not rise fast enough to the desired value. This accumulation may eventually lead to a temperature runaway. We investigated the possibility of such an event for reactions of the type "chemically enhanced mass transfer" or "fast" and found that only low distribution coefficients, i.e. $10^{-4}$ or lower, can lead to accumulation. At higher distribution coefficients, the mass transfer rate across the interface of a well-mixed dispersion is generally sufficient to prevent accumulation. A thermal runaway in the fast regime exerts a moderate effect, because the effective activation energy is halved. Calculations for the "instantaneous" reaction regime, regarded as a special case of fast reactions, show that there is no runaway possible.

\section{Introduction}

In our model of the indirectly cooled SBR, component B is present at the start and the second component $A$ is added at a constant feed rate, until a stoichiometric ratio has been attained. The components $\mathrm{A}$ and $\mathrm{B}$ are either pure or diluted with inert solvents. A and B react to form products $\mathrm{C}$ and $\mathrm{D}$. The heat of reaction is removed by a flow of coolant through a coil or a jacket. The general set-up of such a cooled SBR is illustrated in Fig. 1.

The temperature in the reactor and the concentrations of $\mathrm{A}$ and $\mathrm{B}$ as functions of time can be found by solving the heat and mass balances around the reactor. The following assumptions are made for the mass and heat balances:

- volumes are additive;

- no phase inversion occurs during the reaction;

- the reaction is of first order with respect to reactants A and $B$, and reactions occur in only one phase;

- reaction equation is written as

$$
\nu_{\mathrm{A}} \mathrm{A}+\nu_{\mathrm{B}} \mathrm{B}=\nu_{\mathrm{c}} \mathrm{C}+\nu_{\mathrm{D}} \mathrm{D}
$$

Components $\mathrm{B}$ and $\mathrm{D}$ remain in the continuous phase $c$, the phase already present at the start of the batch. Components $\mathrm{A}$ and $\mathrm{C}$ remain in the dispersed phase $d$ which is usually formed as soon as supply is turned on. $\mathrm{C}$ is the desired product.

- there is no mixing enthalpy, only reaction enthalpy.

- product UA of heat transfer area and overall heat transfer coefficient is proportional to the liquid volume in reactor.

- initial temperature of reactor contents is equal to the mean coolant temperature, which remains constant.

* Dr. ir. M. Steensma, Akzo Chemicals, 7400 AA Deventer, The Netherlands, and Prof. Dr. ir. K.R. Westerterp, Chemical Reaction Engineering Laboratories, Twente University, P.O. Box 217, 7500 AE Enschede, The Netherlands.
The basic equations and definitions describing the thermal phenomena in a cooled SBR, in which the above liquid-liquid reaction is carried out, are presented elsewhere [1,2]. The thermal balance in dimensionless form reads: ${ }^{1)}$

$\frac{\mathrm{d} \tau}{\mathrm{d} \theta}=\frac{1}{1+\varepsilon \theta R_{\mathrm{u}}} \quad\left(\Delta \tau_{\mathrm{ad}, 0} \quad \frac{\mathrm{d} \zeta_{\mathrm{B}}}{\mathrm{d} \theta}-\left(\varepsilon R_{\mathrm{H}}+U^{*} \mathrm{Da}(1+\varepsilon \theta)\right)\left(\tau-\tau_{\mathrm{c}, \mathrm{eff}}\right)\right)$.

This equation describes the dimensionless reactor temperature $\tau$ as a function of the dimensionless parameters time $\theta$, conversion rate $\mathrm{d} \zeta_{\mathrm{B}} / \mathrm{d} \theta$, adiabatic temperature rise $\Delta \tau_{\mathrm{ad}}$, cooling intensity $U^{*}$, feed period $\mathrm{Da}$, coolant temperature $\tau_{\mathrm{e}, \text { eff }}$, fractional volume increase $\varepsilon$, and heat capacity ratio of the two phases $R_{\mathrm{H}}$. For the definitions, see the list of symbols. The effect of the volume increase of the continuous phase during conversion was found to be insignificant and was thus neglected in the above equation. In this mathematical description, the dimensionless conversion rate $\mathrm{d} \zeta_{\mathrm{B}} / \mathrm{d} \theta$ is the only parameter dependent on the kinetic regime.

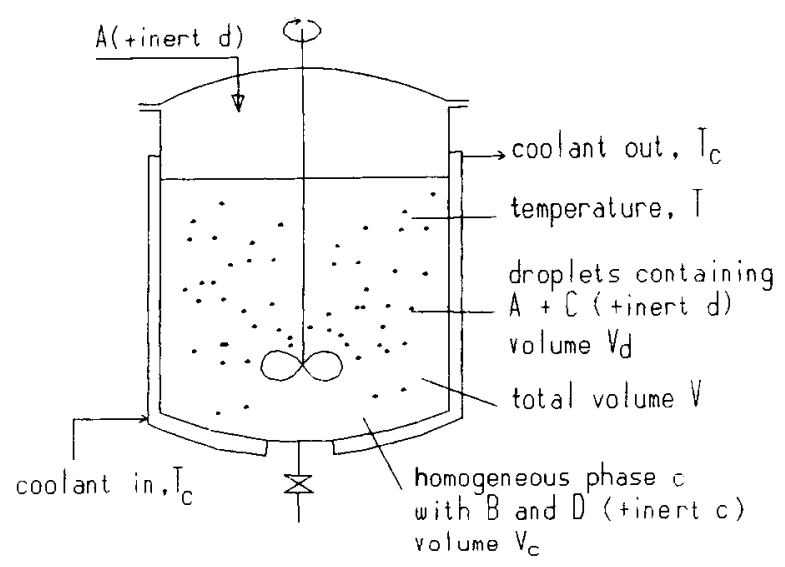

Fig. 1. Operation of a liquid-liquid semibatch reactor.

1) List of symbols at the end of the paper. 
Explicit correlations for $\mathrm{d} \zeta_{\mathrm{B}} / \mathrm{d} \theta$ can be derived under certain conditions, such as low solubility in the other phase, reaction in only one phase and no change of kinetic regime after the start of conversion.

The target temperature is the hypothetical reaction temperature as a function of time for an instantaneous reaction, resulting in $\mathrm{d} \zeta_{\mathrm{B}} / \mathrm{d} \theta=1$, until $\theta=1$. The starting temperature for this hypothetical reaction has been selected in such a way that a smoothly decreasing temperature - time profile is obtained. An expression for the target temperature $T_{\mathrm{ta}}$ is:

$$
T_{\mathrm{ta}}=T_{\mathrm{c}}+\frac{1.05 \Delta T_{\mathrm{ad}, 0}}{\varepsilon R_{\mathrm{H}}+U^{*} \mathrm{Da}(1+\varepsilon \theta)} .
$$

The definition of target temperature permits exact definitions of the thermal phenomena of marginal ignition, thermal runaway and QFS-reaction. The latter type QFS indicates rapid onset, fair conversion and smooth temperature profile and represents a reaction on the verge of dangerous accumulation.

Further concepts introduced are the exothermic number and initial reactivity in a cooled reactor, and the boundary diagram in which the above-mentioned thermal phenomena are represented in a logical way. The initial reactivity and exothermic numbers Ry and Ex, respectively, are defined as

$$
\mathrm{R}_{\mathrm{y}}=\frac{\left(\nu_{\mathrm{A}} / \nu_{\mathrm{c}}\right) \mathrm{Da} \exp \left(\gamma\left(1-1 / \tau_{\mathrm{c}, \text { eff }}\right)\right) \mathrm{RE}}{\varepsilon R_{\mathrm{H}}+U^{*} \mathrm{Da}} .
$$

$\mathrm{RE}$ is the reactivity enhancement factor to be defined in section 3 ,

and $\quad \mathrm{Ex}=\frac{\gamma T_{\mathrm{R}}^{2}}{T_{\mathrm{c}}^{2}} \frac{\Delta \tau_{\mathrm{ad} .0}}{\varepsilon R_{\mathrm{H}}+U^{*} \mathrm{Da}}$.

The boundary diagram is valid if the initial temperature $T_{\mathrm{o}}$ is equal to the coolant temperature $T_{\mathrm{c}}$. For $T_{\mathrm{o}}>T_{\mathrm{c}}$, the region of dangerous accumulation narrows until, at $T_{\mathrm{o}} \approx T_{\mathrm{ta}}$, it ceases to exist. For $T_{\mathrm{o}}<T_{\mathrm{c}}$, the region of dangerous accumulation increases.

\section{Conditions for a Runaway Occurrence During a Fast Reaction}

\section{2.l General Differences Between Fast and Slow Regimes}

The differences between slow and fast regimes for reactions carried out in a semibatch reactor are shown in Figs 2 and 3 which are valid for a reaction in the dispersed phase and based on a number of common parametric values. It is postulated that a reaction in the dispersed phase is more critical with respect to accumulation than one in the continuous phase. The relevant distribution coefficient is thus $m_{\mathrm{B}}$.

For Fig. 2, the Hatta number is $\mathrm{Ha}=0.2$, and mass transfer rates are not chemically enhanced. The concentration drop in the boundary layer of the reaction phase is less than $5 \%$. The

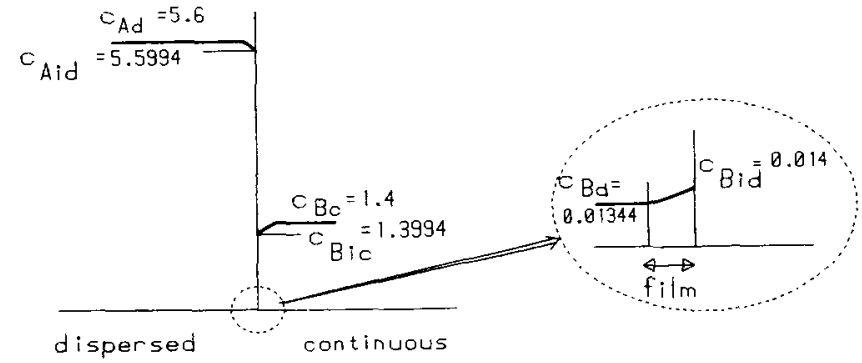

Fig. 2. Example of concentration profiles for reactants A and B during a semibatch, liquid-liquid reaction. Slow reaction in the dispersed phase. Concentrations are in $\mathrm{kmol} / \mathrm{m}^{3}$. Conditions: $\theta=0.5, \zeta_{\mathrm{B}}=0.3, \varepsilon=0.5$, $d_{\mathrm{b}}=60 \times 10^{-6} \mathrm{~m}, k_{1}=10^{-4} \mathrm{~m} / \mathrm{s}, \mathrm{d} \zeta_{\mathrm{B}} / \mathrm{d} \theta=2.5, c_{\mathrm{AD}}=8 \mathrm{kmol} / \mathrm{m}^{3}$, $c_{\mathrm{Bo}}=2 \mathrm{kmol} / \mathrm{m}^{3}, V_{\mathrm{Ro}}=1 \mathrm{~m}^{3}, t_{\mathrm{D}}=36000 \mathrm{~s}, \nu_{\mathrm{A}}=\nu_{\mathrm{B}}=1, m_{\mathrm{B}}=0.01$, $k_{\mathrm{l}, \mathrm{I}, \mathrm{d}}=0.124 \mathrm{~m}^{3} / \mathrm{kmol} \mathrm{s}, \mathrm{Ha}=0.2$ and $\mathrm{D}_{\mathrm{B}}=10^{-9} \mathrm{~m}^{2} / \mathrm{s}$.

Hinterland ratio $\mathrm{Al}$, given by $\mathrm{Al}=$ volume of reaction phase/ volume of film (Westerterp et al. [3]) for the case of reaction in the dispersed phase is rather small if the droplet size is small.

For the usual values of diffusivity $D=10^{-9} \mathrm{~m}^{2} / \mathrm{s}$, the mass transfer coefficient $k_{1}=10^{-4} \mathrm{~m} / \mathrm{s}$ and average droplet diameter of $60 \times 10^{-6} \mathrm{~m}$, it is found that $\mathrm{Al}=2.37$. This low Hinterland ratio $\mathrm{Al}$ implies that the influence of the interface curvature becomes apparent. Nevertheless, the parameter $\mathrm{Al} \times$ $\mathrm{Ha}^{2}$ is still reasonably small, namely 0.09 in our example, and hence the degree of utilization of the reaction phase is close to unity, according to the established theory [3]. Hence, a low value of $\mathrm{Al}$ does not as such constitute a problem in the slow reaction regime.

For the construction of Fig. 3, the value of $k_{1,1, d}$ is increased by a factor of 100 to satisfy the condition for a fast reaction, namely $\mathrm{Ha}>2$. At the same time, the distribution coefficient $m_{\mathrm{B}}$ is made much smaller, namely $2 \times 10^{-4}$ in order to prevent the dimensionless conversion rate from rising to much above unity. In Fig. 3, its value is taken as 2.5.

\subsection{Conversion Rates in Fast Regime}

Going from a slow to a fast reaction, the bulk of the reaction phase becomes increasingly unimportant, the only remaining important factor being the interfacial area. The conversion rates are known from literature [3] and for fast reactions in the continuous and dispersed phases are given by

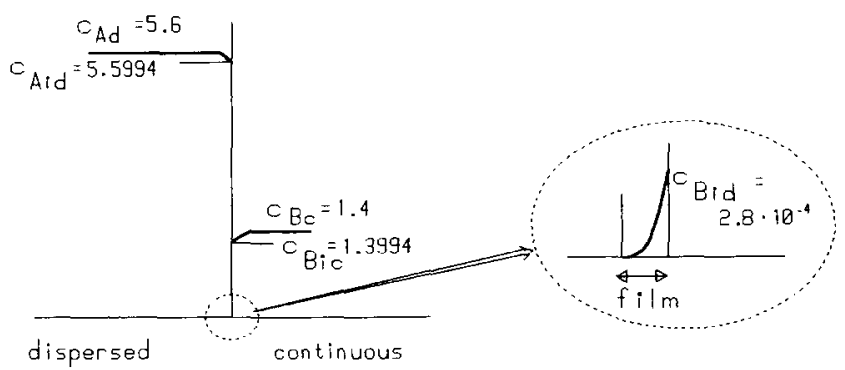

Fig. 3. Example of concentration profiles for reactants A and B during a semibatch, liquid-liquid reaction. Fast reaction in the dispersed phase. Parameters as in Fig. 2, except $m_{\mathrm{B}}=2 \times 10^{-4}, k_{\mathrm{l}, \mathrm{l}, \mathrm{d}}=12.4 \mathrm{~m}^{3} / \mathrm{kmol} \mathrm{s}$ and $\mathrm{Ha}=2$. 


$$
\begin{aligned}
& r_{\text {fast }, \mathrm{c}}=a c_{\mathrm{Aic}}\left(k_{1,1, \mathrm{c}} D_{\mathrm{A}} c_{\mathrm{Bc}}\right)^{1 / 2}, \\
& r_{\text {fast }, \mathrm{d}}=a c_{\mathrm{Bid}}\left(k_{1,1, \mathrm{~d}} D_{\mathrm{B}} c_{\mathrm{Ad}}\right)^{1 / 2} .
\end{aligned}
$$

It is important to mention the variability of some factors in Eqs (1) and (2). The interfacial area is given by the standard expression:

$a=6 \varepsilon_{\mathrm{d}} / d_{\mathrm{b}}=6 \varepsilon \theta /(1+\varepsilon \theta)$.

The parameters $\varepsilon$ and $\theta$ in this expression are unambiguously defined for a semibatch reaction. Equations for the mean droplet diameter are available from literature, but their use is restricted to conditions of constant power input per unit volume by the impeller, and constant interfacial tension. Constant power input per unit volume is only possible if the agitator speed is continually adjusted to the increasing volume during the feed period, which seems rather impractical during production. The interfacial tension during a reaction may also vary in an unpredictable way.

The distribution coefficients $m_{\mathrm{B}}$ or $m_{\mathrm{A}}$, associated with concentrations $c_{\mathrm{Ac}}$ and $c_{\mathrm{Bd}}$, can often be described by a ClausiusClapeyron type of dependence as $\ln \left(m_{\mathrm{B}}\right)$ or $\ln \left(m_{\mathrm{A}}\right)$ vs. $1 / T$, with a very small slope. For example, for toluene in $70.2 \%$ sulphuric acid, a slope of $3430 \pm 200 \mathrm{cal} / \mathrm{gmol}$ is found [4]. A reactant might also be "salted out" during reaction or, in the opposite case, become more soluble due to a mutual solvent effect or change in the polarity. A strongly irregular behaviour of the distribution coefficient is found for nitric acid in toluene in the presence of sulphuric acid [5].

Figs 2 and 3 show that the concentration drop of the reactant transferred across the interface is negligible in the non-reaction phase. Therefore, the approximations $c_{\mathrm{Ac}}=m_{\mathrm{A}} c_{\mathrm{Ad}}$ and $c_{\mathrm{Bd}}=$ $m_{\mathrm{B}} c_{\mathrm{B}}$ in Eqs (1) and (2) respectively are justified. Similarly, the drop in concentration of the compound not transferred through the interface is negligible for its own phase and, therefore, in Eqs (1) and (2), the use of the bulk concentrations $c_{\mathrm{Bc}}$ and $c_{\mathrm{Ad}}$, respectively, is justified. The criteria for these important simplifications are derived later in the text.

Eqs (1) and (2) are found both by applying the film theory and the penetration theory. The next example shows that only during a small part of the droplet's life does molar flux have the extreme value obtained just after the droplet's formation.

Let us assume a fully baffled reactor vessel with net volume of $V=1.5 \mathrm{~m}^{3}$, equipped with a standard disc-and-flat-blade turbine. The volume of the bottom part amounts to approximately $0.25 \mathrm{~m}^{3}$. Thus, the cylindrical part is $H=1.17 \mathrm{~m}$ high and the turbine diameter is $d_{\text {turbine }}=0.39 \mathrm{~m}$.

Turbulent stirring at a high energy input of $2.0 \mathrm{~kW} / \mathrm{m}^{3}$ is applied. The power number $N_{\mathrm{P}}$ is 4.6 [6] and the rotational speed to achieve this high energy input is $n=4.2 \mathrm{~s}^{-1}$. The height of the turbine blades, $w$, is $0.2 d_{\text {turbine }}$ and the total radial liquid flow induced by the turbine is roughly

$$
\phi_{\mathrm{v}} \approx w d_{\text {turbine }} \pi n d_{\text {turbine }} \approx 0.155 \mathrm{~m}^{3} / \mathrm{s} \text {. }
$$

The lifetime of the droplet before it coalesces and breaks up again in the high shear field of the impeller is therefore around $10 \mathrm{~s}$. The parameter $k_{1,1 \mathrm{c}} c_{\mathrm{Bc}}$ or $k_{1,1 \mathrm{~d}} c_{\mathrm{Ad}}$ is equivalent to $\left(\text { Ha } k_{1}\right)^{2} / D$, according to the definition of the Hatta number, and equals $10 \mathrm{Ha}^{2}$ for $k_{\mathrm{l}}=10^{-4} \mathrm{~m} / \mathrm{s}$ and $D=10^{-9} \mathrm{~m}^{2} / \mathrm{s}$. Hence, for the fast reaction regime $\mathrm{Ha}>2$, the parameter $k_{1,1 \mathrm{c}} c_{\mathrm{Bc}} t^{*}$ or $k_{1,1, \mathrm{~d}} c_{\mathrm{Ad}} t^{*}$ has at least a value of 400 . The known correlation for the time averaged molar flux from $t=0$ to $t=t^{*}$ for a fast reaction in the dispersed phase, $J_{\mathrm{B}}=c_{\mathrm{Bld}}\left(k_{1,1, \mathrm{~d}} c_{\mathrm{Ad}} D_{\mathrm{B}}\right)^{1 / 2} \times$ $\times\left(1+1 /\left(2 k_{1,1, \mathrm{~d}} c_{\mathrm{Ad}} t^{*}\right)\right)$ becomes identical to $\mathrm{Eq}$. (2), since the conversion rate $r$ for a liquid-liquid reaction is the product of the molar flux $J$ and the interfacial area $a$. A similar derivation for a fast reaction in the continuous phase yields Eq. (1).

Summarizing the differences between slow and fast reactions, it is observed that the apparent reaction order with respect to the component already present in the reaction phase becomes $1 / 2$, the apparent activation energy is halved and the interfacial area appears explicitly in the equation for the conversion rate. The reactor behaviour during strong accumulation is believed to be fairly similar in both regimes:

- the combination of a low initial temperature and a small interfacial area in the initial period causes accumulation of unreacted $\mathrm{A}$ in the dispersed phase;

- due to the exponential temperature dependence of the reaction rate, a thermal runaway is possible;

- generally, the solubility also increases with temperature, which will enhance the transport through the interaface and accelerate the development of runaway conditions;

- the reaction leading to a runaway can also occur in the continuous phase, but the accumulation always pertains to the reactant in the dispersed phase.

A fast reaction does not necessarily imply a high conversion rate in the reactor as a whole, despite relatively high bulk concentrations. A fast reaction only implies that the component just transferred to the reaction phase is converted already within the hypothetical film with a thickness $D / k_{1}$. The conversion rate is directly proportional to the interfacial area and the relevant distribution coefficient $m_{\mathrm{B}}$ or $m_{\mathrm{A}}$. Only a very low solubility can cause a runaway reaction in the fast regime of $\mathrm{Ha}>2$, which can be explained as follows.

The molar supply rate $\phi_{\text {moiar,A }}$ of reactant $\mathrm{A}$ to the reactor equals $\nu_{\mathrm{A}} / \nu_{\mathrm{B}} c_{\mathrm{Bo}} V_{\mathrm{ro}} / t_{\mathrm{D}}$, which is of the order of $0.001 \mathrm{kmol} / \mathrm{s}$ for an industrial reactor with $V_{\mathrm{ro}}=1 \mathrm{~m}^{3}$. Accumulation can only occur if $\phi_{\text {molar,A }}$ significantly exceeds the conversion rate $r$ for an extended period of time.

Let us assume that the relevant distribution coefficient is $m_{\mathrm{A}}$. The reactant $A$ must be transferred from the dispersed phase through the interface to the reaction film in the continuous phase, where it is completely converted. The rate is given by the following equations:

$J_{\mathrm{A}}=k_{\mathrm{I}, \mathrm{d}}\left(c_{\mathrm{Ad}}-c_{\mathrm{Aid}}\right)=m_{\mathrm{A}} c_{\mathrm{Aid}} k_{\mathrm{l}, \mathrm{c}} \mathrm{Ha}_{\mathrm{c}}$.

The equation for the overall transfer rate is given by

$J_{\mathrm{A}}=k_{1, \mathrm{eff}}\left(c_{\mathrm{Ad}}-c_{\mathrm{Ac}}\right)=k_{1, \mathrm{eff}} c_{\mathrm{Ad}}$ 
resulting in an effective transfer flux, determined by:

$$
\frac{1}{k_{1, \text { eff }}}=\frac{1}{k_{1, \mathrm{~d}}}+\frac{1}{m_{\mathrm{A}} k_{1, \mathrm{c}} \mathrm{Ha}_{\mathrm{c}}} \text { or } k_{\mathrm{l}, \mathrm{eff}}=\frac{m_{\mathrm{A}} k_{1, \mathrm{c}} \mathrm{Ha}_{\mathrm{c}}}{\frac{k_{1, \mathrm{c}}}{k_{1, \mathrm{~d}}}\left(m_{\mathrm{A}} \mathrm{Ha}_{\mathrm{c}}+\frac{k_{1, \mathrm{~d}}}{k_{1, \mathrm{c}}}\right)} \text {. }
$$

If, at the same time, the relationships $k_{1, \mathrm{~d}} \approx k_{1, \mathrm{c}}$ and $m_{\mathrm{A}} \mathrm{Ha}_{\mathrm{c}} \ll 1$ hold, then $k_{\mathrm{i}, \text { eff }} \approx m_{\mathrm{A}} \mathrm{Ha}_{\mathrm{c}} k_{1, \mathrm{c}}$. Hence, under conditions of $k_{\mathrm{l}, \mathrm{d}}$ $\approx k_{1, \mathrm{c}}$ and $m_{\mathrm{A}} \mathrm{Ha}_{\mathrm{c}} \ll 1$, the value of $k_{1, \mathrm{eff}}$ is determined by the chemical reaction in the film, and the mass transfer resistance in the non-reaction phase is relatively unimportant. Substitution of the above result into the general expression for the conversion rate $r=J_{\mathrm{A}} a$, gives $r=a m_{\mathrm{A}} c_{\mathrm{Ad}} \mathrm{Ha}_{\mathrm{c}} k_{\mathrm{l}, \mathrm{c}}$.

Similarly, in case of a fast reaction in the dispersed phase, for which $m_{\mathrm{B}}$ is the relevant distribution coefficient, we have $r=$ $a m_{\mathrm{B}} c_{\mathrm{Bc}} \mathrm{Ha}_{\mathrm{d}} k_{1, \mathrm{~d}}$. Danger of accumulation is imminent if the conversion rate $r$ is less than the molar feed rate per unit volume, or $r V<\phi_{\text {molar, } \mathrm{A}}$. Evaluation for typical parameter values such as $c_{\mathrm{Ad}} \approx c_{\mathrm{Bo}} \approx 5 \mathrm{kmol} / \mathrm{m}^{3}$ (in case of imminent danger of accumulation $c_{\mathrm{Ad}} \approx c_{\mathrm{AD}}$ and $c_{\mathrm{Bc}} \approx c_{\mathrm{Bo}}$ ), molar feed rate $\phi_{\text {molar, } \mathrm{A}}=0.001 \mathrm{kmol} / \mathrm{s}$ and $k_{\mathrm{l}, \mathrm{c}}=10^{-4} \mathrm{~m} / \mathrm{s}$ yields the following criterion for large accumulation, which may result in a runaway:

$a V m_{\mathrm{A}} \mathrm{Ha}_{\mathrm{c}}<2$ or $a V m_{\mathrm{B}} \mathrm{Ha}_{\mathrm{d}}<2$.

Because, under practical conditions $a V \gg 2 \mathrm{~m}^{2}$, we have $m_{\mathrm{A}} \mathrm{Ha}_{\mathrm{c}}$ or $m_{\mathrm{B}} \mathrm{Ha}_{\mathrm{B}} \ll 1$, and hence the concentration profiles in the vicinity of the interface are as depicted in Fig. 3, and the approximations $c_{\mathrm{Ac}}=m_{\mathrm{A}} c_{\mathrm{Ad}}$ and $c_{\mathrm{Bd}}=m_{\mathrm{B}} c_{\mathrm{Bc}}$ are justified. For $a V m_{\mathrm{A}} \mathrm{Ha}_{\mathrm{c}}$ or $a V m_{\mathrm{B}} \mathrm{Ha}_{\mathrm{d}}<2$, the reaction rate cannot match the feed rate of reactant $\mathrm{A}$ and a strong accumulation will occur. The assumption of $k_{1, \mathrm{c}} \approx k_{1, \mathrm{~d}} \approx 10^{-4} \mathrm{~m} / \mathrm{s}$ is valid for small droplets present in well stirred liquid-liquid systems. Their usual diameters range from 50 to $100 \mu \mathrm{m}$ if the power input by turbine stirrer is 2 to $3 \mathrm{~kW} / \mathrm{m}^{3}$. The estimated terminal velocity is below $10^{-3} \mathrm{~m} / \mathrm{s}$ and the Reynolds number Re is below $5 \times 10^{-3}$ which is well in the Stokes's region. The condition for a constant mass transfer coefficient, derivable from the limiting Sherwood number $\mathrm{Sh}=6.6$ for a spherical droplet, is a Fourier number $F o=D t / d_{\mathrm{b}}{ }^{2}$ in excess of 0.1 [7]. This is already the case at $0.5 \mathrm{~s}$ after the formation of the droplet. Our conclusion is that the coefficient $k_{1, d}$ for mass transfer in the droplet is constant and completely determined by diffusion. This is confirmed by several studies, e.g. by Streicher and Schügerl [8] who examined droplets of 3 to $5 \mathrm{~mm}$ in diameter, held on a capillary in stagnant water $(\operatorname{Re} \approx 0)$, and found that pure diffusion occurs. The critical diameter below which a liquid droplet becomes rigid is usually taken as 1 to $2 \mathrm{~mm}$ [9]. For the much smaller droplet sizes in our study, pure diffusion will prevail.

\subsection{Conversion Rates in Dimensionless Form}

A suitable mathematical expression for the mean droplet diameter in a fully baffled vessel with a turbine stirrer is given by van Heuven and Beek [10] as:

$d_{\mathrm{b}}=d_{\mathrm{b}, \mathrm{o}}\left(1+2.5 \varepsilon_{\mathrm{d}}\right)$ where $d_{\mathrm{b}, \mathrm{o}}=0.047 \mathrm{We}^{-0.6} d_{\text {turbine }}$ is the droplet diameter at zero hold-up. The Weber number, We, is the ratio of the dispersing force exerted by the stirrer to interfacial tension of the liquid being dispersed, as given by

$$
\mathrm{We}=\varrho_{\mathrm{c}} N^{2} d_{\text {turbine }}^{3} / \sigma_{\mathrm{r}} .
$$

Other sources yield comparable correlations:

$d_{\mathrm{b}}=d_{\text {turbine }}\left(1+4.47 \varepsilon_{\mathrm{d}}\right) 0.081 \mathrm{We}^{-0.6}$, as found by Coulaloglou and Tavlarides [11], and

$d_{\mathrm{b}}=d_{\text {turbine }}\left(1+4 \varepsilon_{\mathrm{d}}\right) 0.06 \mathrm{We}^{-0.6}$, as found by Giles et al. [12].

Eq. (1), describing the conversion rate in the case of a fast reaction in the continuous phase, can be transformed to:

$r_{\mathrm{fast}, \mathrm{c}}=\frac{6}{d_{\mathrm{b}, 0}}\left(k_{1,1, \mathrm{c}} D_{\mathrm{A}}\right)^{1 / 2} m_{\mathrm{A}} c_{\mathrm{Ad}} c_{\mathrm{Bc}}^{1 / 2} \frac{\left(V_{\mathrm{d}} / V\right)}{1+2.5\left(V_{\mathrm{d}} / V\right)}$

Analogously, from Eq. (2) for a fast reaction in the dispersed phase:

$r_{\text {fast }, \mathrm{d}}=\frac{6}{d_{\mathrm{d}, 0}}\left(k_{1,1, \mathrm{~d}} D_{\mathrm{B}}\right)^{1 / 2} c_{\mathrm{Ad}}^{1 / 2} m_{\mathrm{B}} c_{\mathrm{Bc}} \frac{\left(V_{\mathrm{d}} / V\right)}{1+2.5\left(V_{\mathrm{d}} / V\right)}$.

By using the definitions of $c_{\mathrm{Ad}}$ and $c_{\mathrm{Bc}}$ and the dimensionless conversion rate and assuming no change in the volume of the continuous phase due to reaction [2], the dimensionless conversion rate for a reaction in the continuous phase becomes:

$$
\begin{aligned}
\left(\frac{\mathrm{d} \zeta_{\mathrm{B}}}{\mathrm{d} \theta}\right)_{\text {fast }, \mathrm{c}}= & t_{\mathrm{D}} \frac{6 m_{\mathrm{A}}}{d_{\mathrm{b}, 0}}\left(k_{1,1, \mathrm{c}} D_{\mathrm{A}}\right)^{1 / 2} c_{\mathrm{Bo}}^{1 / 2} \times \\
& \times \frac{\left(\nu_{\mathrm{A}} / \nu_{\mathrm{C}}\right)\left(\theta-\zeta_{\mathrm{B}}\right)\left(1-\zeta_{\mathrm{B}}\right)^{1 / 2}}{1+2.5 \varepsilon \theta /(1+\varepsilon \theta)}
\end{aligned}
$$

and for a reaction in the dispersed phase:

$$
\begin{aligned}
\left(\frac{\mathrm{d} \zeta_{\mathrm{B}}}{\mathrm{d} \theta}\right)_{\text {fast }, \mathrm{d}}= & t_{\mathrm{D}} \frac{6 m_{\mathrm{B}}}{d_{\mathrm{b}, 0}}\left(k_{1,1, \mathrm{~d}} D_{\mathrm{B}}\right)^{1 / 2}\left(\frac{\nu_{\mathrm{B}}}{\nu_{\mathrm{A}}} c_{\mathrm{Bo}}^{1 / 2}\right) \times \\
& \times \frac{\left(\nu_{\mathrm{A}} / \nu_{\mathrm{C}}\right)\left(\theta-\zeta_{\mathrm{B}}\right)^{1 / 2}\left(1-\zeta_{\mathrm{B}}\right)(\varepsilon \theta)^{1 / 2}}{1+2.5 \varepsilon \theta /(1+\varepsilon \theta)}
\end{aligned}
$$

\subsection{Operating Considerations}

In case of fair solubilities during a fast reaction, accumulation is very unlikely as the value of $a V m_{\mathrm{A}} \mathrm{Ha}_{\mathrm{c}}$ or $a V m_{\mathrm{B}} \mathrm{Ha}_{\mathrm{d}}$ will easily be above 2 for a well-mixed dispersion. However, if the supply of A is continued during an agitator failure, restart of the stirrer will cause an immediate temperature runaway, due to the suddenly high mass transfer rate. The rate of temperature increase amounts, under nearly adiabatic conditions, to:

$$
\frac{\mathrm{d} T}{\mathrm{~d} t}=k_{\mathrm{l}} a\left(m_{\mathrm{A}} c_{\mathrm{Ad}} \text { or } m_{\mathrm{B}} c_{\mathrm{Bc}}\right) \frac{\Delta H_{\mathrm{r}}}{\varrho c_{\mathrm{p}}} \mathrm{Ha}
$$


where $\Delta H_{\mathrm{r}}$ is the heat of reaction and $\varrho c_{\mathrm{p}}$ the heat capacity of the reactor contents. Insertion of typical values gives a rate of temperature increase of the order of $500 \mathrm{Ha}\left(m_{\mathrm{A}}\right.$ or $\left.m_{\mathrm{B}}\right) \mathrm{K} / \mathrm{s}$ or $0.1 \mathrm{~K} / \mathrm{s}$. The normal cooling area installed cannot cope with such a high rate of heating. Therefore, an automatic supply shut-off in the case of a power failure is indispensable.

\section{Boundary Diagrams for Fast Reactions}

The calculations for the fast reaction category show the existence of the same thermal phenomena of QFS-reaction, marginal ignition and temperature overshoot as for slow reactions [2]. The boundary diagrams for fast reaction regimes are given in Figs 4 and 5 for reactions in the dispersed and the continuous phase, respectively.

The definition of reactivity is determined by the expression for the dimensionless conversion rate, in analogy to our approach for slow reactions. For such reactions, the reactivity number Ry is:

$$
\begin{aligned}
\mathrm{Ry}= & \frac{\left(v_{\mathrm{A}} / v_{\mathrm{C}}\right)}{\varepsilon R_{\mathrm{H}}+U^{*} \mathrm{Da}} \frac{\mathrm{Da}\left(m_{\mathrm{A}} \text { or } m_{\mathrm{B}}\right) \kappa_{\mathrm{c} . \text { eff }}}{\varepsilon}= \\
& \frac{\left(v_{\mathrm{A}} / v_{\mathrm{C}}\right)\left(m_{\mathrm{A}} \text { or } m_{\mathrm{B}}\right) \mathrm{Da} \exp \left(\gamma\left(1-T_{\mathrm{R}} / T_{\text {c.eff }}\right)\right)}{\varepsilon R_{\mathrm{H}}+U^{*} \mathrm{Da}}
\end{aligned}
$$

in which the Damköhler number is defined as $\mathrm{Da}=t_{\mathrm{D}} k_{\mathrm{R}} c_{\mathrm{Bo}}$. The term $\left(\nu_{\mathrm{A}} / \nu_{\mathrm{C}}\right) \mathrm{Da}\left(m_{\mathrm{A}}\right.$ or $\left.m_{\mathrm{B}}\right)$ in the reactivity number Ry stems from the expression for the conversion rate, which reads in the case of slow reactions:

$$
\mathrm{d} \zeta / \mathrm{d} \theta=\left(\nu_{\mathrm{A}} / \nu_{\mathrm{C}}\right) \mathrm{Da}\left(m_{\mathrm{A}} \text { or } m_{\mathrm{B}}\right) f\left(\theta, \zeta_{\mathrm{B}}, \varepsilon \theta, \kappa\right) \text {. }
$$

The function $f\left(\theta, \zeta_{\mathrm{B}}, \varepsilon \theta, \kappa\right)$ contains the variables previously unknown. It is logical to rewrite the dimensionless conversion rate expressions for the fast reactions in a similar way. Eq. (6) is rearranged in such a way that relevant dimensionless groups for the reactivity definition appear separate from the function $f\left(\theta, \zeta_{\mathrm{B}}, \varepsilon \theta, \kappa\right)$

$$
\begin{array}{rl}
\left(\frac{\mathrm{d} \zeta_{\mathrm{B}}}{\mathrm{d} \theta}\right)_{\text {fast }, \mathrm{c}} & \mathrm{Da}\left(\frac{D_{\mathrm{A}}}{k_{1,1, \mathrm{c}, \mathrm{R}} c_{\mathrm{Bo}}}\right)^{1 / 2}\left(\frac{v_{\mathrm{A}}}{v_{\mathrm{C}}}\right)\left(\frac{6 m_{\mathrm{A}}}{d_{\mathrm{b} .0}}\right) \times \\
& \times \frac{\left(\theta-\zeta_{\mathrm{B}}\right)\left(1-\zeta_{\mathrm{B}}\right)^{1 / 2} \kappa^{1 / 2}}{1+2.5 \varepsilon \theta /(1+\varepsilon \theta)} .
\end{array}
$$

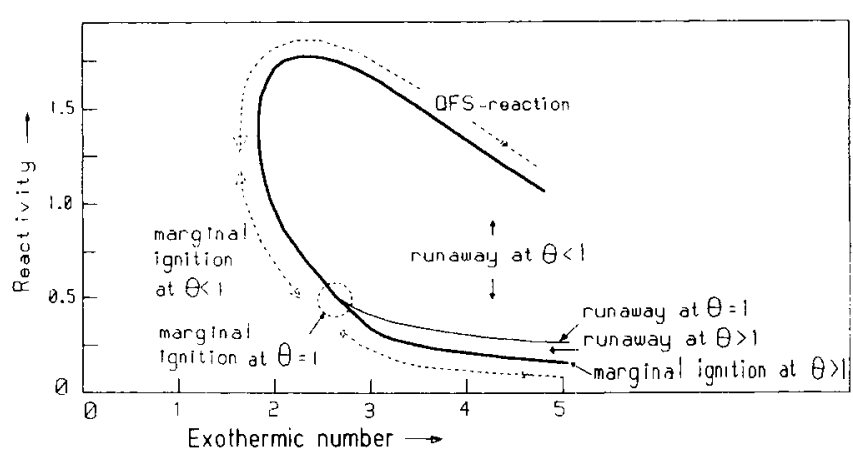

Fig. 4. Boundary diagram for a fast reaction in the dispersed phase. $U^{*} \mathrm{Da} / \varepsilon$ $=10$, and $\mathrm{R}_{\mathbf{H}}=1$

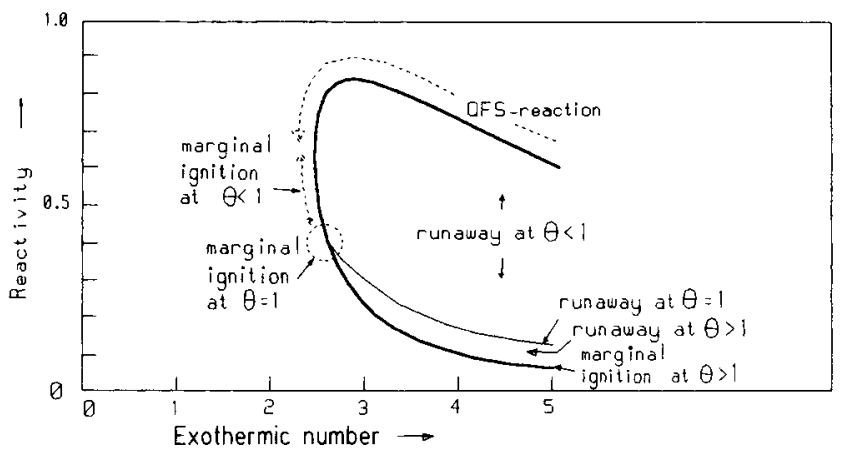

Fig. 5. Boundary diagram for a fast reaction in the continuous phase $U^{*} \mathrm{Da} / \varepsilon=10$, and $R_{\mathrm{H}}=1$.

Now, in the Damköhler number, $k_{\mathrm{R}}=k_{1,1, \mathrm{c}, \mathrm{R}}$. On account of this definition, and the term $\left(D_{\mathrm{A}} k_{1,1, \mathrm{c}} c_{\mathrm{Bo}}\right)^{1 / 2}$ in the conversion rate expression for the fast reaction regime, the constant term $\left(D_{\mathrm{A}} / k_{1,1, \mathrm{c}, \mathrm{R}} c_{\mathrm{Bo}}\right)^{1 / 2}$ emerges in Eq. (8).

Similarly, for a fast reaction in the dispersed phase, given by Eq. (7):

$$
\begin{aligned}
\left(\frac{\mathrm{d} \zeta_{\mathrm{B}}}{\mathrm{d} \theta}\right)_{\text {fast }, \mathrm{d}}= & \mathrm{Da}\left(\frac{6 m_{\mathrm{B}}}{d_{\mathrm{b}, \mathrm{o}}}\right)\left(\frac{D_{\mathrm{B}} v_{\mathrm{B}}}{k_{1,1, \mathrm{~d}, \mathrm{R}} c_{\mathrm{Bo}} v_{\mathrm{A}}}\right)^{1 / 2}\left(\frac{v_{\mathrm{A}}}{v_{\mathrm{C}}}\right) \times \\
& \times \frac{\left(\theta-\zeta_{\mathrm{B}}\right)^{1 / 2}\left(1-\zeta_{\mathrm{B}}\right)(\varepsilon \theta)^{1 / 2} \kappa^{1 / 2}}{1+2.5 \varepsilon \theta /(1+\varepsilon \theta)} .
\end{aligned}
$$

Now, in the Damköhler number, $k_{\mathrm{R}}=k_{1,1, \mathrm{~d}, \mathrm{R}}$.

In Eqs (8) and (9), dimensionless groups appear to represent the mass transfer enhancement in the dimensionless conversion rates. We will call these the reactivity enhancement factors, $\mathrm{RE}$, defined as:

$$
\begin{aligned}
& \mathrm{RE}_{\mathrm{fast}, \mathrm{c}}=\frac{6 m_{\mathrm{A}}}{d_{\mathrm{b}, 0}}\left(\frac{D_{\mathrm{A}}}{k_{1,1, c, \mathrm{R}} c_{\mathrm{Bo}}}\right)^{1 / 2} \text { for reaction in the con } \\
& \text { tinuous phase, }
\end{aligned}
$$

We observe that for a two-phase system and a fast reaction, the value of RE is proportional to $m_{\mathrm{A}}$ or $m_{\mathrm{B}}$ and to $1 / d_{\mathrm{b}, \mathrm{o}}$.

In the above derivations, the original definition of the dimensionless reaction rate constant $\kappa$ according to $\kappa=k_{1,1} / k_{1,1, \mathrm{R}}$ was used.

The expression for the dimensionless conversion rate for the fast reaction regime contains the term $\kappa^{1 / 2}$, as opposed to $\kappa$ in the slow reaction regime, and as a consequence the reactivity should contain the term $\kappa_{\mathrm{c}}{ }^{1 / 2}$ :

$\kappa_{\mathrm{c}}{ }^{1 / 2}=\exp \left(0.5 \gamma\left(1-1 / \tau_{\mathrm{c}}\right)\right)$.

The definition of the initial reactivity number $\mathrm{Ry}$ for the fast reaction regime, based on the above-mentioned considerations, is: 
$\mathrm{Ry}=\frac{\left(v_{\mathrm{A}} / v_{\mathrm{C}}\right) \mathrm{Da} \mathrm{RE}_{\mathrm{fast}} \exp \left(0.5 \gamma\left(1-T_{\mathrm{R}} / T_{\mathrm{C}}\right)\right)}{\varepsilon R_{\mathrm{H}}+U^{*} \mathrm{Da}}$

in which the reactivity enhancement factor RE is given by Eq. (10) or (11). Fig. 6 represents the boundary diagram for a fast reaction in the dispersed phase, for a number of values of $U^{*} \mathrm{Da} / \varepsilon$. Fig. 7 does the same for a fast reaction in the continuous phase.

\section{Check on Validity of the Fast Reaction Model}

The effectively halved activation energy yields a much smoother temperature overshoot in the case of unfavourable starting conditions, see Figs 8 and 9. For nitrations, the activa tion energies range from 59 to $75 \mathrm{MJ} / \mathrm{kmol}$ [13]. Other investigators [14] found higher values of up to $84 \mathrm{MJ} / \mathrm{kmol}$, measured in a homogeneous system. In dimensionless terms, the latter value means $\gamma=33.6$ if the reference temperature $T_{R}$ is $300 \mathrm{~K}$. Fig. 10 presents a typical QFS-condition for a fast reaction in the dispersed phase. Analysis of the QFS-cases for fast reactions leads to a maximum conversion rate of $\mathrm{d} \zeta_{\mathrm{B}} / \mathrm{d} \theta \approx$ 1.5 during the supply period.

Basis for the use of boundary diagrams (Figs 4 through 7) is that all thermal phenomena must meet the condition of $\mathrm{Ha}>$ 2 . This implies that the reacting system is already fast at the lowest temperature, namely at the marginal ignition condition, derived from $R y \approx 0.2$ for a fast reaction in the dispersed phase and $\mathrm{Ry} \approx 0.07$ for a fast reaction in the continuous

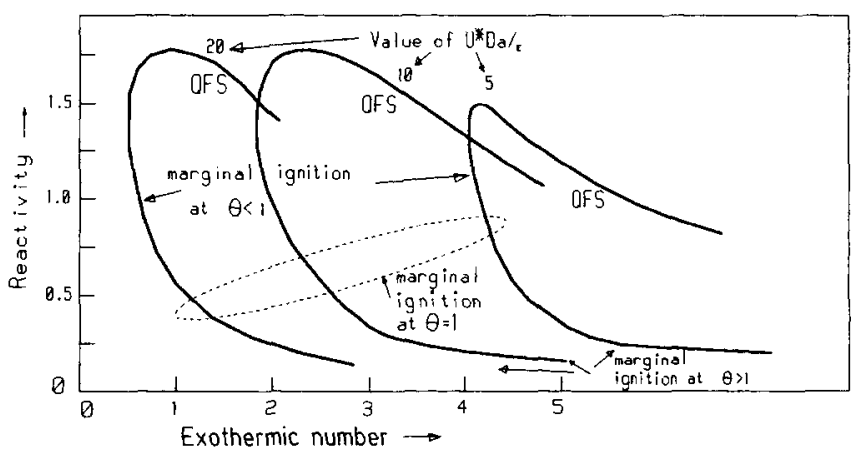

Fig. 6. Influence of $U^{*} \mathrm{Da} / \varepsilon$ on boundary lines. Fast reaction in the dispersed phase, $R_{\mathrm{H}}=1$.

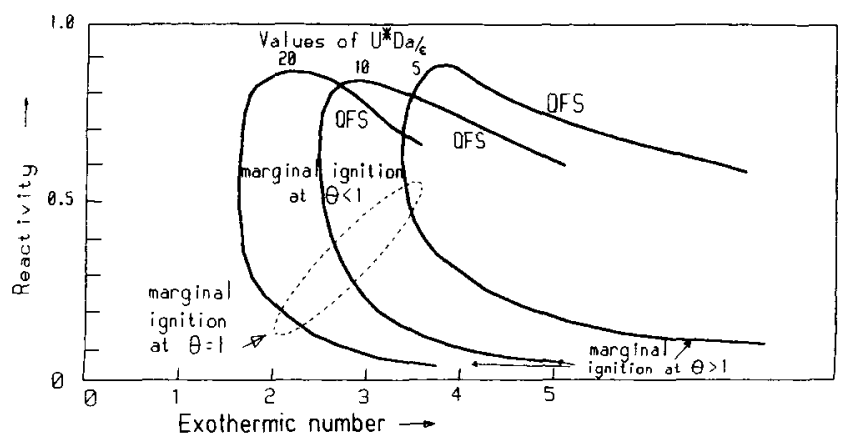

Fig. 7. Influence of $U^{*} \mathrm{Da} / \varepsilon$ on boundary lines. Fast reaction in the continuous phase, $R_{\mathrm{H}}=1$.

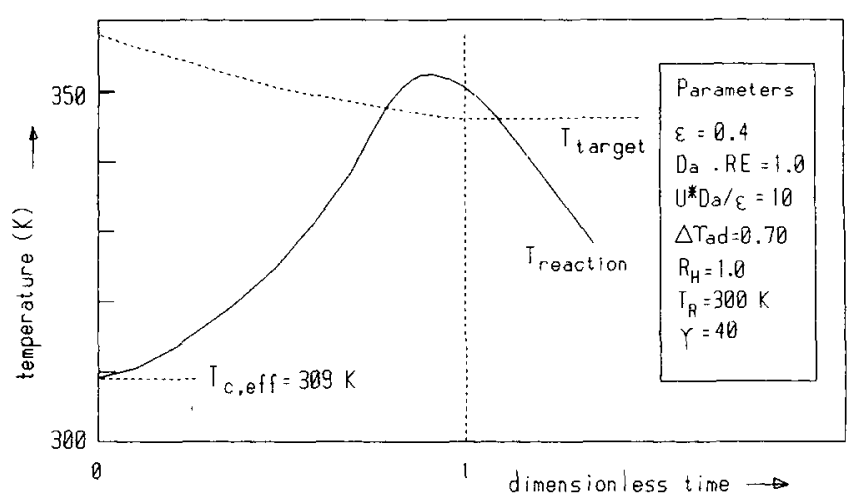

Fig. 8. Runaway for a fast reaction in the dispersed phase.

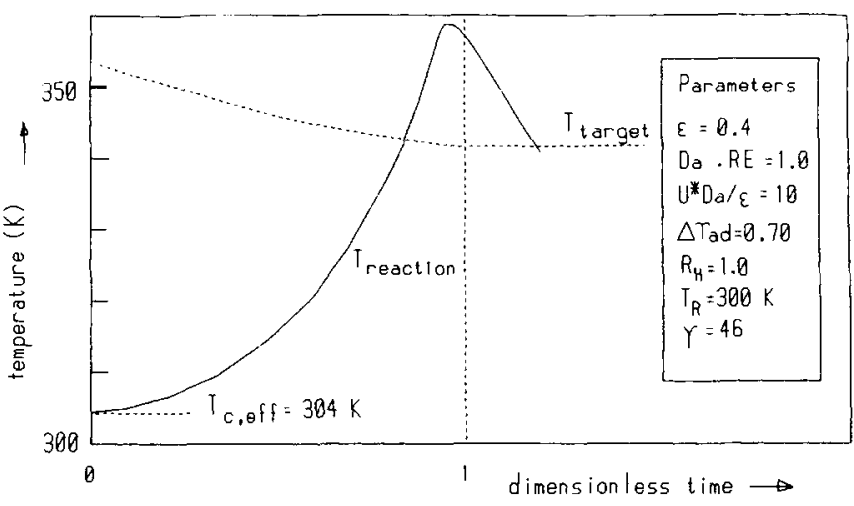

Fig. 9. Runaway for a fast reaction in the dispersed phase. Influence of slightly higher activation energy than in Fig. 8.

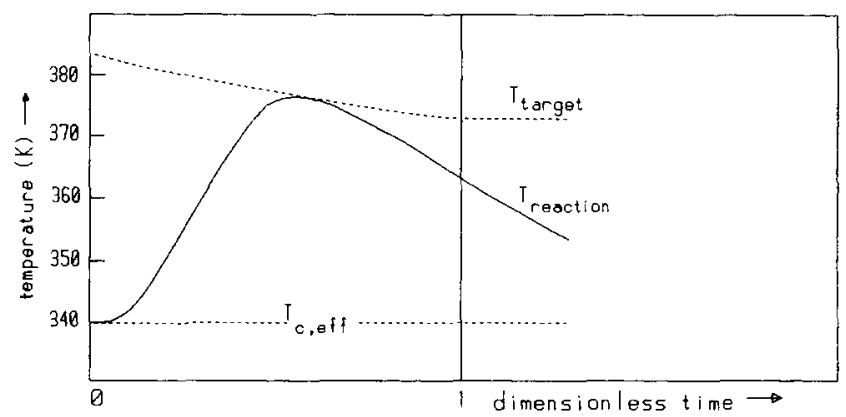

Fig. 10. Typical QFS-condition for a fast reaction in the dispersed phase. Parameters: $\varepsilon=0.4, \gamma=33.6$, Da $\mathrm{RE}_{\mathrm{fast}, \mathrm{d}}=1, \Delta \tau_{\mathrm{ad}}=0.6, T_{\mathrm{R}}=300$ $\mathrm{K}, U^{*} \mathrm{Da} / \varepsilon=10, R_{\mathrm{H}}=1$, and $T_{\mathrm{c}}=340 \mathrm{~K}$.

phase. Note that this approach is exactly opposite to the validity check for slow reactions, where we had to show that the reaction at the highest conceivable temperature, apart from a runaway reaction, is still in the slow regime. Starting with a fast reaction in the dispersed phase, in Eq. (13), the definitions of $\mathrm{RE}_{\text {fast,d }}$ according to Eq. (11), $\kappa$ at $T_{\mathrm{c}}$, and the Damköhler number $\mathrm{Da}$ for this regime are substituted. Secondly, the resulting equation is rearranged to:

$$
\begin{aligned}
\mathrm{Ry}_{\mathrm{fast}, \mathrm{d}}= & \text { minimum required }=\left(\frac{v_{\mathrm{A}} v_{\mathrm{B}}}{v_{\mathrm{c}^{2}}} \frac{c_{\mathrm{Bo}}}{c_{\mathrm{Ad}}}\right)^{1 / 2} \times \\
& \times \frac{\left(c_{\mathrm{A}} D_{\mathrm{B}} k_{1,1, \mathrm{~d}}\right)^{1 / 2}}{\varepsilon R_{\mathrm{H}}+U^{*} \mathrm{Da}} \frac{6 t_{\mathrm{D}} m_{\mathrm{B}}}{d_{\mathrm{b}, 0}}=0.2 .
\end{aligned}
$$


Inserting $\mathrm{Ha}_{\mathrm{d}}=\frac{\left(k_{1,1, \mathrm{~d}} c_{\mathrm{Ad}} D_{\mathrm{B}}\right)^{1 / 2}}{k_{\mathrm{l}, \mathrm{d}}}$ into Eq. (14) yields:

$\frac{\mathrm{Ha}_{\mathrm{d}} m_{\mathrm{B}}}{d_{\mathrm{b}, 0}}=0.2 \frac{\varepsilon R_{\mathrm{H}}+U^{*} \mathrm{Da}}{6 k_{\mathrm{l}, \mathrm{d}} t_{\mathrm{D}}\left(\frac{v_{\mathrm{A}} v_{\mathrm{B}}}{v_{\mathrm{C}} v_{\mathrm{C}}} \frac{c_{\mathrm{Bo}}}{c_{\mathrm{Ad}}}\right)^{1 / 2}}$.

Solving Eq. (15) for $\mathrm{Ha}>2$ gives a correlation of the form:

$m_{\mathrm{B}}<0.1 d_{\mathrm{b}, \mathrm{o}} h\left(\varepsilon, R_{\mathrm{H}}, U^{*} \mathrm{Da}, k_{1}, t_{\mathrm{D}}, \nu_{\mathrm{A}}, \nu_{\mathrm{B}}, \nu_{\mathrm{C}}, c_{\mathrm{Bo}}, c_{\mathrm{A}}\right)$

Evaluation of the function $h\left(\varepsilon, R_{\mathbf{H}}, \ldots . c_{\mathrm{A}}\right)$ for a number of practical cases does not show much variation, namely $h(\varepsilon$, $\left.R_{\mathrm{H}}, \ldots . c_{\mathrm{A}}\right)=5$ to 20 , and a reasonably accurate check whether the condition $\mathrm{Ha}>2$ will be met in practice is therefore:

$m_{\mathrm{B}}<(0.5$ to 2$) d_{\mathrm{b}, \mathrm{o}}$

Eq. (16) gives the most stringent condition for the use of the boundary diagram as it covers even the marginal ignition case, which occurs at much lower temperatures than the more important QFS-case. A similar condition for the QFS-case is less stringent since the lowest value of Ry is approx. 0.9 (Fig. 4), which yields the condition $m_{\mathrm{B}}<(2.5$ to 10$) d_{\mathrm{b}, \mathrm{o}}$.

A similar check for the fast reaction in the continuous phase yields:

$\frac{\mathrm{Ha}_{\mathrm{c}} m_{\mathrm{A}}}{d_{\mathrm{b}, 0}}=0.07 \frac{\varepsilon R_{\mathrm{H}}+U^{*} \mathrm{Da}}{6 k_{\mathrm{l,c}} t_{\mathrm{D}}\left(\frac{v_{\mathrm{A}}^{2}}{v_{\mathrm{C}} 2} \frac{c_{\mathrm{Bo}}}{c_{\mathrm{Bc}}}\right)^{1 / 2}}$.

By analogy, it is clear from Eq. (17) that the condition for a fast reaction in the continuous phase is approximately met if:

$m_{\mathrm{A}}<(0.2$ to 0.7$) d_{\mathrm{b}, \mathrm{o}}$.

This condition is less stringent if only QFS-cases are considered and reads $m_{\mathrm{A}}<(1.5$ to 6$) d_{\mathrm{b}, \mathrm{o}}$.

In case conditions (16) and (18) are not met, the reaction will start in the slow reaction regime. During supply, the regime may switch to the enhanced mass transfer regime once the dispersion is heated up sufficiently.

\section{The Regime of Instantaneous Reaction}

The instantaneous reaction can be considered as a special case of fast reaction, where no chemical limitations seem to exist. During an instantaneous reaction, the rate is so high that $\mathrm{A}$ and $B$ do not occur simultaneously at the same site and the reaction zone reduces to a plane in the boundary layer of the reaction phase. For the fast reaction regime, we derived the condition for which the concentration drop in the non-reaction phase is relatively unimportant, being $m_{\mathrm{A}} \mathrm{Ha} \ll 1$. The concentration drop in the non-reaction phase becomes increasingly important if $m_{\mathrm{A}} \mathrm{Ha}>0.1$. We must check whether conditions exist in the instantaneous reaction regime under which the overall conversion rate may become much slower than the reactant supply rate to the reactor.

The maximum overall transfer rate during an instantaneous reaction in the dispersed phase when component $B$ must be transferred across the interface is derived from the mass balance at the hypothetical reaction plane at distance $\delta_{\mathrm{r}}$ from the interface, see Fig. 11, and for the film model:

$J_{\mathrm{B}}=k_{\mathrm{l}, \mathrm{c}}\left(c_{\mathrm{Bc}}-c_{\mathrm{Bic}}\right)=m_{\mathrm{B}} c_{\mathrm{Bic}} D_{\mathrm{Bd}} / \delta_{\mathrm{r}}$, for component $\mathrm{B}$, and $J_{\mathrm{A}}=c_{\mathrm{Ad}} D_{\mathrm{Ad}} /\left(\delta-\delta_{\mathrm{r}}\right)$ for component $\mathrm{A}$.

Furthermore: $J_{\mathrm{A}}=\nu_{\mathrm{A}} / \nu_{\mathrm{B}} J_{\mathrm{B}}$ and $\delta=D_{\mathrm{Ad}} / k_{1, \mathrm{~d}}$.

Elimination of the unknown $\delta_{\mathrm{r}}$ and $c_{\mathrm{Bic}}$, and a few rearrangements give:

$J_{\mathrm{B}}\left(\frac{1}{k_{\mathrm{l}, \mathrm{c}}}+\frac{D_{\mathrm{Ad}}}{D_{\mathrm{Bd}} m_{\mathrm{B}} k_{\mathrm{l}, \mathrm{d}}}\right)=c_{\mathrm{Bc}}+\frac{\left(\nu_{\mathrm{B}} / \nu_{\mathrm{A}}\right) c_{\mathrm{Ad}} D_{\mathrm{Ad}}}{D_{\mathrm{Bd}} m_{\mathrm{B}}}$,

Assuming $\mathrm{k}_{1, \mathrm{c}} \approx \mathrm{k}_{\mathrm{l}, \mathrm{d}} \approx \mathrm{k}_{1}$ yields:

$J_{\mathrm{B}}=k_{1} c_{\mathrm{Bc}}\left[1+\frac{D_{\mathrm{Ad}}\left(\left(\nu_{\mathrm{B}} c_{\mathrm{Ad}} / \nu_{\mathrm{A}} c_{\mathrm{Bc}}\right)-1\right)}{D_{\mathrm{Bd}} m_{\mathrm{B}}+D_{\mathrm{Ad}}}\right]$

We are dealing with very low distribution coefficients $m \ll$ 1 , otherwise there is no possibility of accumulation at all. Since $D_{\mathrm{Ad}} \approx D_{\mathrm{Bd}}$, we can simplify the above expression to:

$J_{\mathrm{B}}=k_{\mathrm{l}} c_{\mathrm{Bc}}\left[1+\frac{\left(\nu_{\mathrm{B}} c_{\mathrm{Ad}} / \nu_{\mathrm{A}} c_{\mathrm{Bc}}\right)-1}{m_{\mathrm{B}}+1}\right]=k_{1} c_{\mathrm{Ad}}\left(\nu_{\mathrm{B}} / \nu_{\mathrm{A}}\right)$.

Hence, $r=J_{\mathrm{B}} a=k_{1} a c_{\mathrm{Ad}}\left(\nu_{\mathrm{B}} / \nu_{\mathrm{A}}\right)$.

According to the above expression, the distribution coefficient does no longer influence the conversion rate in the regime of the instantaneous reaction. Evaluation of the above expression yields an extreme mass transfer rate of the order of $1 \mathrm{kmol} /$ $\mathrm{s} \mathrm{m}^{3}$.

A similar derivation for an instantaneous reaction in the continuous phase yields an equally high conversion rate $r=$ $k_{1} a c_{\mathrm{Bc}}$.

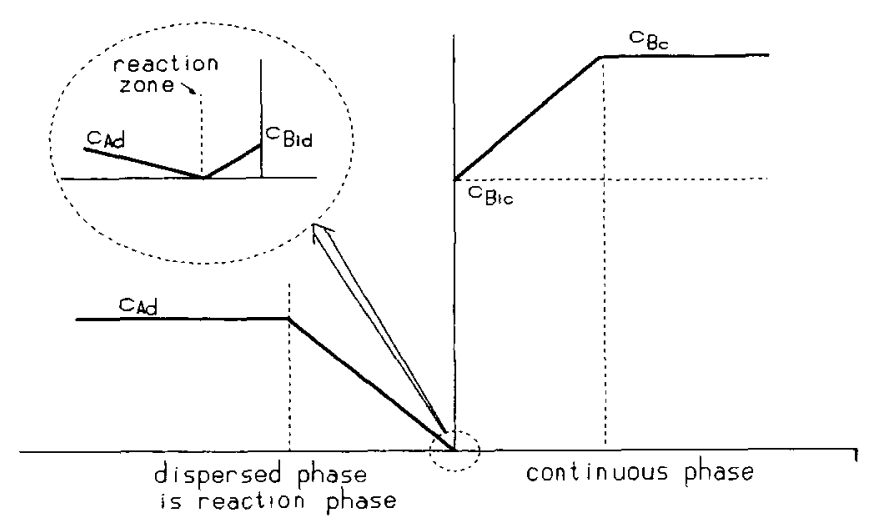

Fig. 11. Concentration profiles in a liquid-liquid dispersion during an instantaneous reaction. Reaction takes place in the dispersed phase. 
Our conclusion is that, in the instantaneous reaction regime, the mass transfer rate in a well-stirred liquid-liquid dispersion is always so high that no measurable accumulation of unreacted A can occur.

\section{Discussion and Conclusions}

The calculations for the fast reaction regime show the existence of the same thermal phenomena as in slow reactions. These can be represented in a boundary diagram, based on the key parameters: dosing rate, initial reactivity, initial cooling rate and potential temperature rise. The most important factors in the definition of reactivity are the droplet size, the distribution coefficients and the Hatta number of the reaction system.

We assumed a liquid-liquid system with technical grade chemicals, mixed with a powerful disperser, to produce droplet sizes in the range from 50 to $100 \mu \mathrm{m}$. The distribution coefficients limit the maximum possible concentration of the reactant transferred across the interface to the reaction phase, and therefore determine the actual reaction rate.

Because of the high mass transfer rates possible during a fast reaction in a well-mixed dispersion, only low values of $m_{\mathrm{A}}$ or $m_{\mathrm{B}}$, approximately $10^{-4}$ or less, can lead to accumulation of unconverted reactant. The condition for the development of accumulative conditions in an industrial reactor reads $a \mathrm{Vm} \mathrm{Ha}$ $<2$. The mass transfer resistance in the non-reaction phase is relatively small as a result of the large interfacial area. In the case of $m \mathrm{Ha}>0.1$, the mass transfer resistance in the nonreaction phase becomes important, e.g. if the regime of instantaneous reaction is entered. There is no danger of accumulation of unconverted reactant as the conversion rates in the instantaneous reaction regime are of the order of 0.1 to $10 \mathrm{kmol} / \mathrm{s} \mathrm{m}^{3}$.

The boundary diagrams as given are fully valid if $m_{\mathbf{B}}<(0.5$ to 2) $d_{\mathrm{b}, \mathrm{o}}$ for a fast reaction in the dispersed phase and $m_{\mathrm{A}}<$ $(0.2$ to 0.7$) d_{\mathrm{b}, \mathrm{o}}$ for a fast reaction in the continuous phase. The requirement for the use of boundary diagrams is less stringent if only QFS-cases are examined.

The runaway event is probably moderate due to the halved energy of activation as compared to its value in the slow reaction regime.

The area in the boundary diagram enclosed between the lines for marginal ignition and QFS-reaction, but beyond the critical exothermic number $\mathrm{Ex}_{\mathrm{c}}$, corresponding to the condition "marginal ignition at $\theta=1$ ", represents the dangerous accumulation phenomenon. Comparing the boundary diagrams for the slow [1, 2] and for the fast regime, we observe, in Table 1 , that the critical exothermic number $\operatorname{Ex}_{\mathbf{c}}$ for the fast regime is not very dependent on the reaction phase. This is contrary to the slow reaction regime where we see a strong dependence on the reaction phase. This is logical as a fast reaction occurs in the interface. Similarly, for the fast reaction regime, the critical reactivity value $R y_{c}$ beyond which there is always sufficient reaction rate to prevent accumulation, is also only marginally dependent on the reaction phase, contrary to the slow reaction regime.
Table 1. Critical exothermic numbers $\mathrm{Ex}_{\mathrm{c}}$, and critical reactivity numbers $\mathrm{Ry}_{\mathrm{c}}$, for fast and slow reaction regimes.

\begin{tabular}{l|ccc|ccc}
\hline Kinetic regime & \multicolumn{3}{|c|}{ Critical number $\mathrm{Ex}_{\mathrm{c}}$} & \multicolumn{3}{c}{ Critical number $\mathrm{Ry}_{\mathrm{c}}$} \\
\hline$U^{*} \mathrm{Da} / \varepsilon$ & 20 & 10 & 5 & 20 & 10 & 5 \\
\hline slow, dispersed & 2.5 & 3 & 3.6 & 0.8 & 0.72 & 0.70 \\
slow, continuous & 4.8 & 6 & 10 & 0.02 & 0.028 & 0.035 \\
fast, dispersed & 1.3 & 2.4 & 4.2 & 1.6 & 1.6 & 1.5 \\
fast, continuous & 2.2 & 2.8 & 3.6 & 0.85 & 0.83 & 0.86 \\
\hline
\end{tabular}

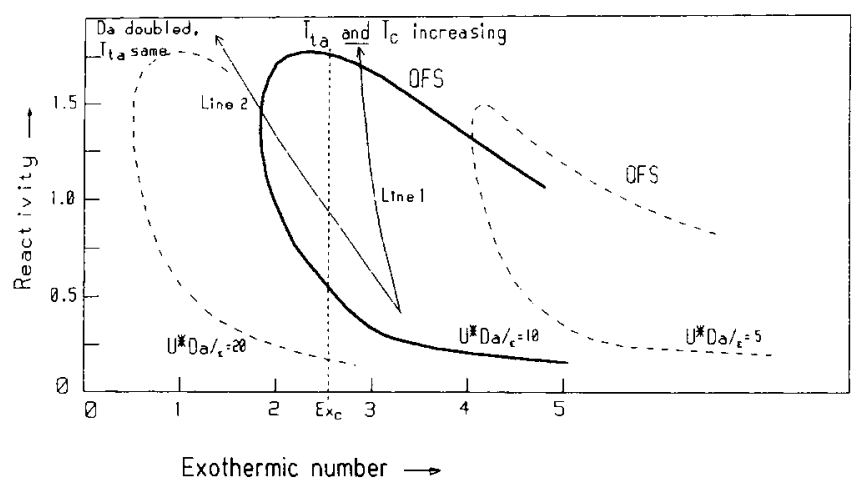

Fig. 12. Two possibilities of preventing occurrence of runaway if intended operation condition leads to accumulation: increase target and cooling temperatures, or increase dosing time and cooling temperature while keeping the same target temperature.

If a reaction has a tendency to accumulation there are a number of solutions to prevent conditions which may lead to a runaway occurrence, see Fig. 12. If a higher target temperature is allowed, probably the best solution is to increase the cooling temperature, whilst maintaining dosing rate, cooling intensity and concentrations, as shown by line 1 in Fig. 12. The target temperature increases by the same amount as the cooling temperature. If a higher target temperature is not allowed, then increasing the cooling temperature and simultaneously reducing the dosing rate is a possibility as shown by line 2 in Fig. 12.

Received: November 29, 1990 [CET 348]

\section{Symbols used}

$\mathrm{Al}$

$\left[\mathrm{m}^{2}\right]$

a

$\left[\mathrm{m}^{2} / \mathrm{m}^{3}\right]$

$\left[\mathrm{kmol} / \mathrm{m}^{3}\right]$

$c_{\mathrm{p}} \quad[\mathrm{J} / \mathrm{kg} \mathrm{K}]$

$d$

D

Da

[m]

$\left[\mathrm{m}^{2} / \mathrm{s}\right]$

[-]

E $\quad[\mathrm{J} / \mathrm{kmol}]$

Ex [-]

Fo [-]

H [m]

$\mathrm{Ha}$ [-] area of cooling coil or jacket

Hinterland ratio, volume of reaction phase/ volume of film

interfacial area per unit volume

molar concentration

heat capacity

diameter

diffusivity

Damköhler number, $\mathrm{Da}=k_{\mathrm{R}} c_{\mathrm{Bo}} t_{\mathrm{D}}$

activation energy

initial exothermic number,

$\mathrm{Ex}=\gamma\left(\frac{T_{\mathbf{R}^{2}}}{T_{\mathrm{c}^{2}}}\right)\left(\frac{\Delta \tau_{\mathrm{ad}, \mathrm{o}}}{\varepsilon R_{\mathrm{H}}+U^{*} \mathrm{Da}}\right)$

Fo $=D t / d_{\mathrm{b}}{ }^{2}$, Fourier number

height (of vessel)

Hatta number, $\mathrm{Ha}=\left(k_{\mathrm{c}} c_{\mathrm{B}} D_{\mathrm{A}}\right)^{1 / 2} / k_{1}$ or

$\mathrm{Ha}=\left(k_{\mathrm{d}} c_{\mathrm{A}} D_{\mathrm{B}}\right)^{1 / 2} / k_{1}$ 


\begin{tabular}{|c|c|c|}
\hline$\Delta H_{\mathrm{r}}$ & {$[\mathrm{J} / \mathrm{kmol}]$} & reaction enthalpy \\
\hline$J$ & {$\left[\mathrm{kmol} / \mathrm{s} \mathrm{m}^{2}\right]$} & molar flux \\
\hline$k_{1,1}$ & {$\left[\mathrm{~m}^{3} / \mathrm{kmol} \mathrm{s}\right]$} & reaction rate constant \\
\hline$k_{1}$ & {$[\mathrm{~m} / \mathrm{s}]$} & mass transfer coefficient \\
\hline$m$ & {$[-]$} & distribution coefficient \\
\hline$n$ & {$\left[s^{-1}\right]$} & stirring speed \\
\hline$N_{\mathrm{p}}$ & & power number of stirrer \\
\hline$R^{\mathrm{p}}$ & {$[\mathrm{J} / \mathrm{kmol} \mathrm{K}]$} & gas constant, $R=8314$ \\
\hline$R_{\mathrm{H}}$ & {$[-]$} & $\begin{array}{l}\text { ratio of specific heat capacities, } \\
\qquad\left(\varrho c_{\mathrm{p}}\right)_{\mathrm{D}} \quad\left(\varrho c_{\mathrm{p}}\right)_{\mathrm{d}}\end{array}$ \\
\hline RE & {$[-1$} & $\begin{array}{l}R_{\mathrm{H}}=\frac{\left(\varrho c_{\mathrm{p}}\right)_{0}}{\left(\varrho c_{\mathrm{p}}\right)_{\mathrm{c}}} \\
\text { reactivity enhancement factor, Eq. (10) or (11) }\end{array}$ \\
\hline Ry & {$[-1$} & initial reactivity parameter, Eq. (13) \\
\hline$r$ & {$\left[\mathrm{kmol} / \mathrm{m}^{3} \mathrm{~s}\right]$} & conversion rate in reactor \\
\hline Sh & {$[-]$} & Sh $=k_{1} d_{\mathrm{b}} / D$, Sherwood number of droplet \\
\hline$T$ & {$[\mathrm{~K}]$} & temperature \\
\hline$t$ & {$[s]$} & time \\
\hline$\Delta T_{\text {ad }}$ & {$[\mathrm{K}]$} & adiabatic temperature rise \\
\hline$\vec{U}^{\mathrm{aa}}$ & {$\left[\mathrm{W} / \mathrm{m}^{2} \mathrm{~K}\right]$} & overall heat transfer coefficient \\
\hline$U^{*}$ & {$[-]$} & cooling number $U^{*}=(U A)_{\mathrm{o}} /\left(\varrho c_{\mathrm{p}} V_{\mathrm{R}} c_{\mathrm{B}}\right)_{\mathrm{o}} k_{\mathrm{R}}$ \\
\hline$V$ & {$\left[\mathrm{~m}^{3}\right]$} & liquid volume in reactor \\
\hline$w$ & {$[\mathrm{~m}]$} & height of turbine \\
\hline We & {$[-1$} & Weber number, We $=\rho n^{2} d^{3}$ turbine $/ \sigma$. \\
\hline
\end{tabular}

\section{Greek symbols}

\begin{tabular}{|c|c|c|}
\hline$\Gamma$ & $1-1$ & relative concentration \\
\hline$\gamma$ & {$[-1$} & $E / R T_{\mathbf{R}}=$ dimensionless activation energy \\
\hline$\Delta \varepsilon_{\mathrm{c}}$ & {$[-\rceil$} & $\begin{array}{l}\text { relative volume increase of continuous phase at } \\
\text { complete conversion, } \Delta \varepsilon_{\mathrm{c}}=\left(V_{\mathrm{c}}-V_{\mathrm{ro}}\right) / V_{\mathrm{ro}}\end{array}$ \\
\hline$\delta$ & {$[\mathrm{m}]$} & thickness of boundary layer, $\delta \approx D / k_{1}$ \\
\hline$\delta_{\mathrm{r}}$ & [m] & distance of reaction plane to interface \\
\hline$\varepsilon$ & {$[-]$} & $\begin{array}{l}\text { relative volume increase at end of dosing, } \\
\varepsilon=\phi_{\mathrm{vD}} t_{\mathrm{D}} / V_{\mathrm{ro}}\end{array}$ \\
\hline$\varepsilon_{\mathrm{d}}$ & {$[-]$} & volume fraction of dispersed phase \\
\hline$\zeta$ & {$[-1$} & conversion \\
\hline$\theta$ & {$[-]$} & $\theta=t / t_{\mathrm{D}}$, dimensionless time \\
\hline$\kappa$ & {$[-]$} & $\kappa=k / k_{\mathrm{R}}$, dimensionless rate constant \\
\hline$\mu$ & {$[-]$} & $\mu=U^{*} \mathrm{Da} / \varepsilon$, dimensionless cooling intensity \\
\hline$\nu$ & {$[-]$} & stoichiometric coefficient \\
\hline$\varrho$ & {$\left[\mathrm{kg} / \mathrm{m}^{3}\right]$} & density \\
\hline$\sigma$ & {$[\mathrm{N} / \mathrm{m}]$} & interfacial tension \\
\hline$\tau$ & {$[-1$} & dimensionless temperature, $\tau=T / T_{\mathrm{R}}$ \\
\hline$\phi_{\mathrm{v}}$ & {$\left[\mathrm{m}^{3} / \mathrm{s}\right]$} & flow rate \\
\hline
\end{tabular}

\section{Subscripts}

A,B.C component $A, B$ or $C$, respectively
ad

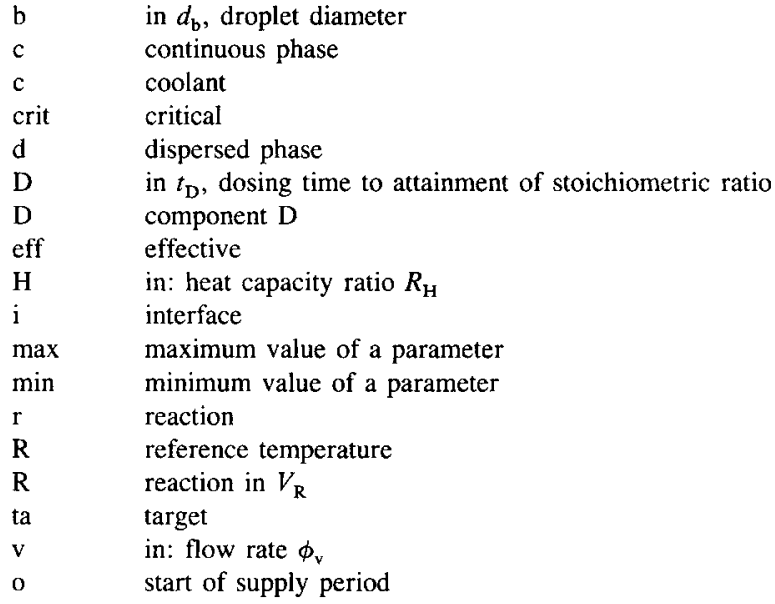

\section{References}

[1] Steensma, M., Westerterp, K.R., Chem. Eng Sci. 43 (1988) No. 8, pp. $2125-2132$.

[2] Steensma, M., Westerterp, K.R., Ind. Eng Chem. Res. 29, (1989) No. 7, pp. $1259-1270$.

[3] Westerterp, K.R., van Swaaij, W.P.M., Beenackers, A.A.C.M., Chemical Reactor Design and Operation 2nd ed. John Wiley \& Sons, Chichester (UK) 1987.

[4] Cox, P.R., Strachan, A.N., Chem. Eng Sci. 27(1972) pp. 457- 463.

[5] Giles, J., Hanson, C., Ismail, H.A.M., Industrial and Laboratory Nitrations, (L.F. Albright and C. Hanson eds.) ACS-Symp. Ser. Vol. 22, Washington D.C. 1976.

[6] Ekato Rühr- und Mischtechnik GmbH, Research and Development of Mixers (Brochure), Schopfheim, Germany 1980.

[7] Beek, W.J., Muttzall, K.M.K., Transport Phenomena, John Wiley \& Sons, Chichester (UK) 1977.

[8] Streicher, R., Schügerl, K., Chem. Eng Sci. 32 (1977) pp. 23-33.

[9] Wesselingh, J., Chem. Eng Process 21 (1987) pp. 9- 14.

[10] van Heuven, J.W., Beek, W.J., De Ingenieur/Chemische Techniek 6, (The Netherlands), 82 (1970) No. 44, pp. 41-60.

[11] Coulaloglou, C.A., Tavlarides, L.L., AIChE J. 22 (1976) pp. $289-297$.

[12] Giles, J.W., Hanson, C., Marsland, J.G., Proc. Int. Solvent Extr. Conference, Society of Chemical Industry, London 1971, No. 1, pp $94-111$.

[13] Kirk \& Othmer, Encyclopaedia of Chemical Technology, Vol. 15, John Wiley \& Sons, Chichester (UK) 1981.

[14] Field, J.P., Strachan, A.N., Ind. Eng Chem. Prod. Res. Dev. 21 (1982) No. 3, pp. $352-355$. 